\title{
Blending for student engagement: Lessons learned for MOOCs and beyond
}

\author{
Amanda P. Montgomery, Denyse V. Hayward, William Dunn, \\ Mike Carbonaro, \& Carl G. Amrhein \\ University of Alberta
}

\begin{abstract}
The purpose of this ongoing, three-year action research study is to explore the digital challenges of student engagement in higher education within the experimental platform of blended learning. Research questions examine the role of digital innovation in supporting diverse learners, as well as building meaningful connections with technology for undergraduate teacher education students. Results from qualitative data collected through instructor journals and field notes and student mid-term and exit surveys during year one, indicate blended learning can be effective for modelling how to use technology to shift learners towards more active agency. The immediacy of the localised university classroom delivered a viable research setting for digital experimentation, while providing a significant lived experience for undergraduates to springboard their future technological practices with K-12 students. Four pedagogical opportunities for digital intentionality in virtual spaces emerged during data analysis and are shared as considerations for future innovation: (1) designing digital resources, (2) scaffolding student learning, (3) learner customisation, and (4) promoting the lived experience. Lessons learned could be effective in helping develop higher quality educational experiences for on-campus students, as well as scaffolding greater engagement in online formats involving more global populations (e.g., massive online open courses MOOCs).
\end{abstract}

\section{Introduction}

Higher education in North America, and around the world, is at a crossroad. The rapid growth of technology and its evolving potential to support the transformation of teaching and learning at post-secondary institutions continues to challenge the fundamental ways in which we view both the university and the communities it serves. The almost frenetic enthusiasm for the massive open online course (MOOC), with its potential to make education more accessible around the globe, is evidence of current tensions challenging our understanding. Significant questions remain as to how to capture such digital learning opportunities while assuring that the integrity of the teaching and learning process remains at the core of our university programs.

Brick and mortar institutions have a long history of centring undergraduate education within face-to-face (F2F) instruction. Indeed, innovations to develop new digital learning formats can create considerable tensions among faculty and within administrative structures. Casanovas (2010) argued that a lack of a transition plan between top-down administration policy and bottom-up individual innovation has the potential to stifle creative implementation and change, even when both support the innovation. Institutions experienced in this kind of transformational process suggest a well-defined university digital policy is critical for effective implementation at the undergraduate level (Owston, York, \& Murtha, 2013).

\section{Opportunities for digital innovation}

Several learning variants exist for university programs considering a move towards more digital innovation. Figure 1 illustrates the potential instructional spectrum from F2F to fully online. Although each format varies in the amount of F2F instruction, class time and credit hours are generally equivalent among all learning variants. At the far left-hand side is the traditional F2F instructional environment that is most familiar in undergraduate programs. As indicated, the number of seats/desks available to students could be a limiting factor in this learning format although large public universities commonly have classrooms that hold as many as 300-600 students. A common variation in the F2F undergraduate class (whether small or large) is the addition of supplemental online instructional resources such as documents, podcasts and wikis, which creates a Web-enhanced F2F class. Universities use a variety of learning management systems 
(LMSs) that serve as a digital portal for students to access these online resources (e.g., Moodle) but F2F instruction remains at the core in this learning format.

\section{Spectrum of F2F within Higher Education}

Note: Required class time is equal in all learning variants

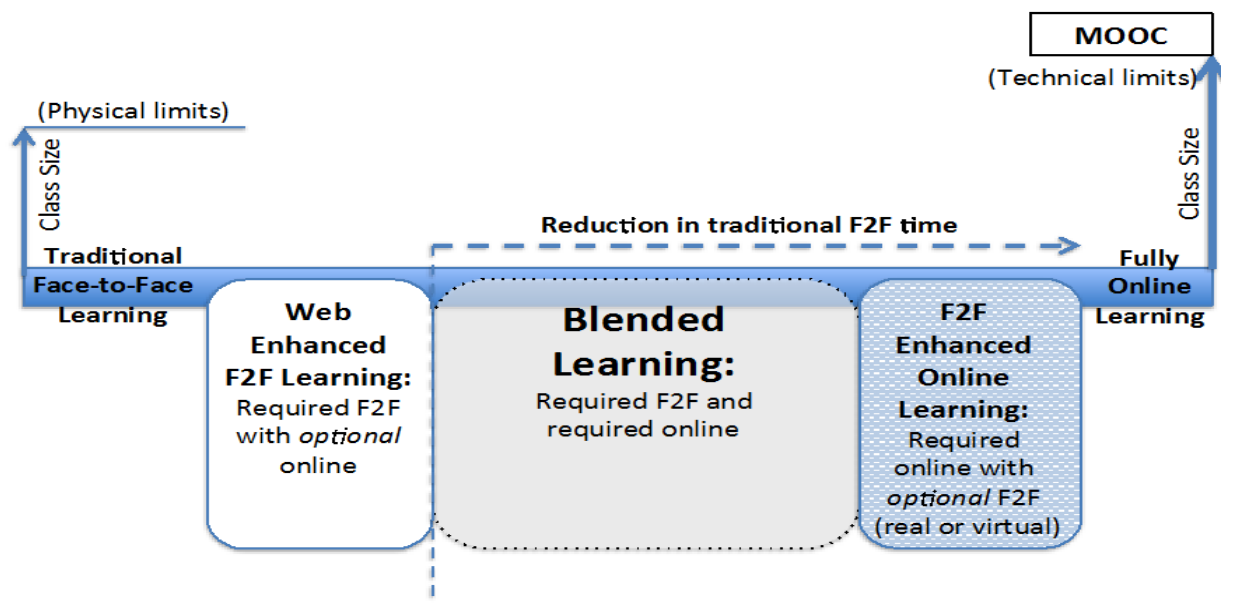

Figure 1. F2F continuum in higher education: Traditional instruction to the MOOC

A university interested in moving further to the right along the digital pathway in Figure 1, would see instructors reducing F2F class time offset by an increase in the time a student spends learning online. The blended learning format consists of both required F2F and online instructional components that are paired together into a blended fusion with technology playing a key role in this integration process. Figure 1 illustrates how this reduction of physical F2F classroom time is a key difference between F2F, Webenhanced F2F and blended learning. Instructors moving even further along the digital spectrum to F2Fenhanced online learning would engage students entirely through online instruction but might choose to enhance this with optional F2F (or synchronous online) labs to offer supplemental instructional help (e.g., question/answer sessions). This is similar to Web-enhanced F2F in that all instruction is offered through one instructional format (in this case, online), while the alternative format (in this case, F2F) is simply an optional component for students. Blended learning, on the other hand, requires some mixture of both instructional formats (i.e., F2F and online) and thus differs from all the other digital instructional designs indicated in Figure 1 in this regard.

At the far right of the F2F spectrum in Figure 1 is the fully online format with all instruction offered completely online through asynchronous and/or synchronous instruction. As indicated, class size can vary from small to very large (e.g., MOOCs), this time not potentially limited by physical space as in the F2F format, but by the current developmental state of technological tools available to the instructor.

\section{The role of student engagement}

A significant challenge facing the adoption of any digital innovation at the undergraduate level is designing pedagogy that provides adequate support for student engagement. Research in higher education indicates student engagement is perhaps the single most important factor in determining successful learning for university students no matter what the university program or instructional format (Trowler \& Trowler, 2010). Defined by the Australian Council for Educational Research (2010) as the "time and effort students devote to educationally purposeful activities” (p. 1), many researchers suggest student engagement is a multifaceted construct that encompasses several dimensions, including psychological (e.g., self-efficacy, individuality of the learner) as well as socio-cultural perspectives (e.g., students' cultural and linguistic background) (Kahu, 2013). For example, research by Schuetz (2008) suggests supporting student agency and motivation are key elements for learner engagement. Bryson and Hand (2007) indicate the need for teachers to provide an invitation to engage through creation of a supportive atmosphere and willingness for conversation, while Kuh, Kinzie, Buckley, Bridges, and Hayek (2006) highlight the importance of collaboration and active learning beside peers to promote student willingness to engage. 
Logistics suggest intentionality regarding student engagement is even more critical for virtual learning spaces, since with the privileges of student flexibility in learning time and space (e.g., asynchronous) comes increased responsibility for individual student motivation. This seems especially relevant in any undergraduate teacher education innovation as such digital courses need to serve the dual role of both supporting student engagement at the university level while at the same time providing opportunity for preservice teachers to gain an increased understanding of how to activate and sustain engagement with their future younger students. Thus, in terms of learner engagement, undergraduate teacher education students need both the opportunity to be engaged as college participants as well as active pre-professional learners, especially when it comes to possibilities with technology.

According to Bell (2001), much of the use of technology in undergraduate teacher education has been "added on to an already full methods class curriculum" (p. 525), with efficiency given priority over “effectiveness and engagement” (Veletsiano, 2010, p. 90). Recent graduates' inability to transfer knowledge learned about technology to supporting student engagement in the K-12 classroom may be indicative of the teaching of such skills out of context in undergraduate classes with no integration into the entire learning process (Koehler, Mishra, \& Yahya, 2007). Embedding technology within the core of an undergraduate teacher education course as is both possible, and necessary. in digital formats (e.g., blended learning, MOOCs), could help instructors bring greater visibility to their undergraduate students regarding how technology might be used to support learner engagement for students of all ages.

\section{MOOCs and blended learning}

Evidence suggests that the MOOCs' potential as an opportunity for digital innovation at the undergraduate level may have prompted many universities to experiment with this new learning format before fully understanding the potential ramifications for student engagement (Haggard, 2013). Certainly, the original conceptualisation of the cMOOC in 2008 in Canada (i.e., Connectivism and Connective Knowledge CCK08) with its potential to link a large number of students through the pedagogic principles of connectivism (i.e., building knowledge through the connections of participants and digital artifacts residing in online environments - Siemens, 2005), held promise for scaling learner engagement within a large online environment.

The business model xMOOCs that followed in 2011 (e.g., Udacity, Coursera) pushed the MOOC back towards a more traditional, behaviourist model of learning (Skinner, 1976) with some consideration for the possible benefits of retrieval learning (Agarwall, Bain, \& Chamberlain, 2012). These new xMOOCs developed course content around modules of pre-made screen captures or video lectures followed by multiple-choice quizzes, with some opportunity for synchronous or asynchronous conversation among participants (Rodriquez, 2012). Even when repackaged into smaller-sized videos in consideration for learner fatigue (Khan, 2012), this dependence by the xMOOC on the talking-head delivery model seemed to perpetuate an unfortunate type of passivity by students that had become all too familiar in the large, university lecture hall (Daniel, 2012). The 5\%-15\% completion rate in many of these xMOOCs is viewed as evidence of a type of disengagement by the learner (Korn \& Levitz, 2013), although some have argued such statistics are due more to the post-degree type of adult learner participating in the early non-credit courses (Haggard, 2013).

The recent evolutionary reconfiguration of some xMOOCs towards a new partnership with blended learning (e.g., blended or distributed MOOCs) serves as clear evidence of higher education's acknowledgement that undergraduate students value community built through F2F instruction (Caufield, Collier, \& Halawa, 2013). This repositioning of the xMOOC within an already existing F2F-oriented digital learning format makes some sense, given research evidence that students appreciate the F2F interactions with peers and instructors offered during blended learning (Owston et al., 2013). Blended learning avoids the high dropout rates found in most xMOOCs, in part, because of its ability to sustain community among learners through the development of F2F conversation outside the virtual classroom (McCarthy, 2010). A recent study by Moskal, Dziuban, and Hartman (2013) comparing over 1,000,000 student responses from undergraduates enrolled in blended courses to other delivery forms (e.g., online, F2F, lecture capture) at the University of Central Florida found a $4 \%$ positive difference in favour of blended learning on the variable of course excellence. Their findings also demonstrate a higher level of academic success and the lowest level of withdrawal from coursework when involving a blended learning modality. 
The importance of utilising such research-based pedagogy in conjunction with digital innovation in higher education is critical, given the financial investment needed by universities as they attempt to leverage technology to build stronger undergraduate programmes. Still, this recent experimental partnering of talking-head videos from off-site created xMOOCs in combination with on-campus F2F time facilitated by a local instructor (e.g., distributed open collaborative courses - DOOCs), may not provide the robust linkage needed to engage undergraduate students in purposeful learning. Research indicates successful blended courses need to consist of a seamless pairing of both online and F2F instruction (Torrisi-Steele \& Drew, 2013), requiring thoughtful pedagogical planning by a discipline expert in order to ensure learning activities are meaningful (So \& Brush, 2008). Indeed, blended learning's reduction in traditional F2F time to include new online instructional components is meant to be a complete rethinking and redesign of instruction, rather than a simple repackaging of existing content (Vaughn, 2007). Although some might argue that the new blended MOOCs' online video content is meant to be used more like a supplementary digital textbook (Skorton \& Altschuler, 2013), research in blended learning suggests both the F2F and online components need to be complementary and interdependent to be successful (Francis \& Shannon, 2013), with technology fully integrated into the instructional process (Turney, Robinson, Lee, \& Soutar, 2009). The pedagogy of blended learning, then, locally designed and fully integrated at the on-campus level of the institution, may offer universities a more viable research space in which to investigate undergraduate student engagement within virtual learning spaces, while providing important evidence for how to use such technology to build a stronger online learning environment in more, global off-campus formats such as MOOCs 2.0.

\section{Purpose}

Utilising blended learning as an experimental platform for addressing issues in student engagement within virtual learning spaces was a recent decision made at the University of Alberta as part of its new digital visioning policy. First initiatives have included providing support for both blended learning course innovation in the Faculty of Education in conjunction with the development of an initial xMOOC in the Faculty of Science. It was hoped that these new blended learning pilots might provide a pathway for greater understanding of learner engagement in the digital environment that could provide parallel opportunities for application in various metamorphoses of the MOOC models. Professors in the Faculty of Education were selected for phase one of the blended learning research because of their already existing experience with the scholarship of teaching and learning, thus providing a solid foundation upon which to build technological experimentation.

Specific experimentation in the Faculty of Education discussed in this article highlighted the opportunity to investigate learner engagement in the virtual environment by examining the intersection between student engagement, blended learning, and undergraduate teacher education. In particular, researchers were interested in examining the role that technological innovation in a blended learning format could play in supporting instructors' goals to support learner engagement for undergraduate students. Researchers were also interested in exploring ways to make such digitally enhanced engagement more visible and meaningful to such students in relation to their future professional practice. This study has been framed by two research questions:

(1) What role can technological innovation in a blended learning course play in supporting diverse learners in undergraduate teacher education courses?

(2) What role can technological innovation in a blended learning course play in connecting undergraduate teacher education students to meaningful experiences with student engagement?

\section{Methodology and research design}

A mixed-methods approach utilising a multi-year action research design was utilised to address the two research questions. Situated within the spirit of participatory human inquiry (Reason \& Bradbury, 2001), methodological opportunity to document both qualitative and quantitative data within the collective action of pedagogical problem solving (i.e., planning, blended course redesign, implementation, and evaluation) was considered critical; this was both for examining the issues of learner engagement from multiple perspectives as well as for "creating new forms of understandings" regarding student engagement for future curricular innovation (Reason \& Bradbury, 2001, p. 2). Qualitative data was determined most appropriate for collection in the first phase of the research, both for informing subsequent quantitative processes as well 
as for providing immediate empowerment for education professors to become more technologically proactive with their practice.

Three cycles of the planning-action-reflection research process were devised to take place over a three-year period (Kemmis, 2001). Figure 2 indicates how the flow of both qualitative and quantitative data collected through instructor field notes and journals, student surveys, and digital analytics was planned so that knowledge generated within each year of a course development cycle could potentially inform the next.

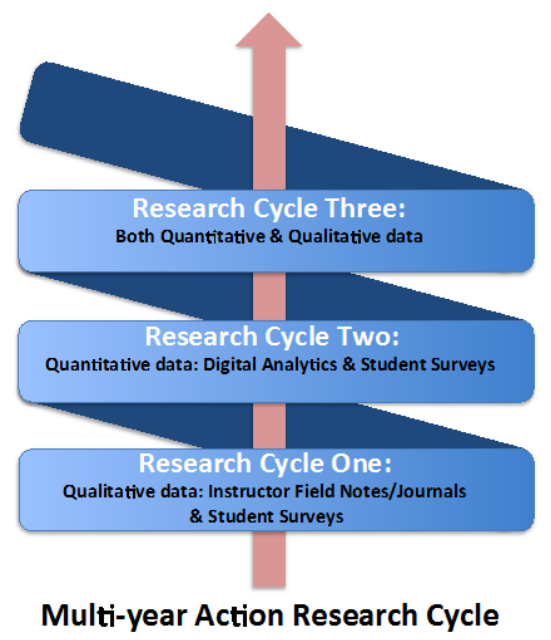

Figure 2. Flow of data collection over three years

This article reports on results in relation to pedagogical innovation work completed during research cycle one (i.e., year one) of this action research process.

\section{Research cycle one Method}

Three F2F courses were selected for blended learning experimentation during this first action research cycle: "Curriculum \& Instruction in Elementary School Music, "Adolescent Language, Literacy \& Culture" and "Inclusive Education: Adapting Instruction for Students with Special Needs". Course selection was based on the diversity in education subject area between courses and their potential impact on students as required courses within the Bachelor of Education (BEd.) program. Intentionality regarding learner engagement within a virtual learning environment was at the forefront of blended course innovation and included focus on three areas of student engagement:

(1) individual students' willingness to activate engagement with the course content/activities (starting engagement)

(2) individual students' willingness to sustain engagement with the course content/activities (sustaining engagement)

(3) individual students' opportunity to view this engagement as meaningful in terms of their own learning (making engagement meaningful).

Each of the three professors was provided support regarding technology by a technology consultant and graduate teaching assistant over a six-month period. One course release was also provided to allow adequate time for the course innovation and implementation process. The overall objective, in these blended learning transformations, was to experiment with content and pedagogical practices through the use of new, creative possibilities with technology, in order to potentially create engaging, flexible, and meaningful learning environments for undergraduate students.

Professors documented their innovation work in reflective journals and field notes as part of the official planning/action/reflection research process. They met regularly to discuss the progress of their individual course development and to share knowledge regarding their observations surrounding technology and learner engagement. Teacher education students enrolled in the three, new blended course formats 
participated in the research through mid-term and exit surveys in order to collect data regarding students' perspectives on the blended learning experience. Qualitative data was the focal point in the first research cycle in an attempt to reveal descriptive evidence to guide future innovations.

\section{Data analysis part I}

An iterative analytical approach guided part one of the data analysis. This process involved the three professors individually sifting through descriptive data detailing their observations of the innovation process as collected through their instructor journals and field notes. Each professor worked separately to synthesise both of these data sources into a newly written narrative documenting their observations and perspectives on the blended learning innovation process (i.e., planning, blended course re-design, implementation, and evaluation). Professors interwove student comments from the mid-term and exit surveys into these narrative documents to help provide context for their instructors' stories and dialogue surrounding learner engagement and virtual learning spaces (Polkinghorne, 1995).

\section{Results}

The three instructor narratives are presented here as qualitative evidence of the professors' experience in relation to the two research questions (Bruner, 1991).

Instructor narrative I - Curriculum \& instruction in elementary school music

Transforming the first teacher education course into a blended learning format provided a unique framework in which to examine technological innovation and student engagement from a psychological perspective (Kahu, 2013). This course involves theoretical and pedagogical content about how children learn in music (i.e., learn musical concepts such as beat, melodic contour), and learn through music (e.g., use music to support learning in literacy or numeracy), thus bringing the challenges of self-efficacy within the performing arts to the research process. Students are generally third- and fourth-year undergraduate students working towards a BEd. in order to qualify to become classroom teachers in elementary schools (K-6), and are not required to have any musical background before enrolling.

The F2F version of the course had been organised around a collaborative approach to learning, centering instruction within the socio-cultural learning theory of shared meaning making among participants (Vygotsky, 1978). Here, engagement had been supported, in part, by viewing students as learning partners; each was responsible for creating shared knowledge about music education within a collaborative environment of music making, thinking, and creating. This idea of the F2F classroom as a mediating space in which to safely explore and reflect upon the musical practices of children was contextualised through Bandura's (1997) social cognitive theory and his notion of self-efficacy that "beliefs of personal efficacy constitute the key factor of human agency” (p. 3). Pedagogical intentionality regarding self-efficacy was considered critical since the undergraduate BEd. students' confidence regarding singing had traditionally been quite poor. Over the years, excellent strategies for using experiential learning in every F2F class session had been developed. These hands-on activities served to scaffold students' musical self-efficacy towards a greater confidence level and willingness to utilise the pedagogical ideas and resources from the class with future elementary school students.

The challenge with moving to blended learning in terms of engagement was in determining creative, digital opportunities for sustaining the already high engagement factor that had been exhibited by students in the F2F version. To address this, the instructor chose to utilise the non-traditional instructional design of a flipped classroom (i.e., student engages with material online first before coming to F2F class) (Baker, 2000); 50\% of the new blended format was reworked as online learning and 50\% remained as F2F oncampus instruction. Careful consideration was given for motivating students' willingness to activate engagement by making sure beginning course activities in the online component met student self-efficacy levels in music, similar to how a video game starts with easy challenges followed by immediate feedback and further levels of complexity (Malone \& Lepper, 1987). Further, diversity in learning styles was considered by developing course materials that were made accessible online through a variety of different modalities: textual (e.g., readings), visual (e.g., videos, screencasts), aural (podcasts), and social media (e.g., online discussions, sharing musical links through Web 2.0 tools). It was evident that students appreciated this opportunity for learning through multiple modalities as revealed in this comment, "There are many different interactive styles provided from articles, to screencasts, to vignettes. These really help 
me from getting bored and stay engaged. I like the diversity offered" (student comment, md-term survey, 2013).

One particular digital learning object received a great deal of comments by students designating it as their favourite. These were instructor created pedagogical vignettes that were designed to model both music content topics, as well as music teaching engagement strategies for $\mathrm{K}-6$ students. These short 3-5 minute videos were filmed unscripted, in the regular university classroom, in an attempt to create a natural teaching feel to visually illustrate important pedagogical ideas for engaging children in musical learning. Noted as valuable by students, many spoke to the significance of how such instructor-made videos stimulated the development of meaningful learning from the beginning of their learning process. As one student commented, "I find the video clips a wonderful bonus as they help cement the knowledge from the textbook" (student comment, exit survey, 2013). As another stated, "I am a huge fan of the online videos supplemented with textbook readings as I find they really appeal to my learning style" (student comment, md-term survey, 2013).

Students' ability to return to these videos later in the course after having gained further knowledge about musical content provided them with a unique opportunity (not previously available in the F2F version) to re-view the vignettes through the subsequent lens of a prospective teacher; thereby, concentrating more on how learning engagement could be supported for their future students. The inclusion of these new videos in the virtual online environment, then, provided a dual scaffold for students; this was both from their perspective as new music students in the course, and then later on, as emerging teachers of young children.

Sustaining engagement was planned for through the interactive, hands-on experiential learning (i.e., kinesthetic) that took place in the weekly F2F class. Already part of the previous F2F format, these activities could now be increased, allowing students even deeper penetration into the content area than had been previously possible in F2F because of time constraints. As one student stated:

I value the live classes as well because that is very important to my learning style ... there is so much hands-on whether we are moving around on our feet singing or using manipulatives at the table. This helps reinforce the videos too (student comment, exit survey, 2013).

New assignments in the online reinforcement portion of the course were made multidimensional, challenging students to situate their new understandings about music within individualised or collaborative projects. Such flexibility made possible through the new digital assignments was intended to support student knowledge so that that meaningful engagement with content could become transformative and potentially disseminate into their future professional spaces. Students responded well to this opportunity to take more ownership in their learning as revealed by this student comment:

I find in this [blended] format we are held accountable for our learning more so than face-toface classes, and for myself, I found that it forces me to manage my time effectively which has been a huge help with my learning (student comment, exit survey, 2013).

Students' positive response to this kind of development of multiple means of accessing and engaging with course content through diverse learning objects (e.g., readings, screencasts, videos, podcasts, online discussions, Web 2.0 social media) points towards the importance of pedagogical intentionality when attempting to transform virtual learning environments into engaging learning experiences. Providing access to content through taped lecture or video as we saw in many early xMOOCs might be viewed as a first step towards activating engagement for the visual learner. However, such solo designs to digital resources may not provide enough support for students with other strengths in learning styles (e.g., aural, oral, textual, kinesthetic). In addition, experimentation in this blended course innovation suggests students' ability to return to these multiple resources later in the course for revisiting through the new lens of a potential teacher was significant. Such observations suggest new opportunities for further exploration of how to magnify this unexpected value of the digital space in supporting student engagement in future small (e.g., blended) or large (e.g., MOOCs) undergraduate digital innovations.

Instructor narrative II - Adolescent language, literacy \& culture

Transforming the second teacher education course into a blended learning format provided another excellent opportunity to address issues of technological innovation and student engagement, this time from 
a sociocultural perspective (Kahu, 2013). In particular, issues of diversity and engagement were addressed through pedagogical experimentation with the culturally diverse undergraduate student population that resided naturally within the teacher education program at the University of Alberta.

The goal of this undergraduate course is to prepare future teachers to work effectively in culturally and linguistically diverse classrooms that have become the face of 21st century K-12 education. In the past, this aim had been addressed within a limited number of curriculum and instruction courses in the teacher education program (e.g., social studies, languages, arts). In 2011, a F2F course on language, literacy, and culture had become a new mandatory component for all students in the secondary school teacher education program, in an effort to emphasise social diversity and inclusiveness across the entire grades 7-12 curriculum.

This expansion of diversity issues for consideration by all students presented some challenges. One key was determining how to make such content more relevant for the wider teacher education student population whose secondary school subject areas were now quite variable in the course (e.g., mathematics, social studies). The immediate solution was to add culturally responsive pedagogy (CRP) as a core concept exploring the fundamental tenet that learning is more meaningful by making it relevant to each individual learner's cultural background (Ladson-Billings, 1995). Ideally, teachers would eventually design instructional contexts in their grades 7-12 classrooms which create opportunities to learn about their students' cultural background from the students themselves, rather than making assumptions based on which cultural or ethnic group they belong to.

Instructors in the newly revised F2F course continued to experience challenges, this time stemming from students' perception of the potential non-relevance of this new CRP content. Some undergraduate students who were preparing to teach school subjects in which language, literacy and culture had not traditionally been an area of focus (e.g., physical education) did not immediately consider this course material to be important for their future teaching practice. For example, one student stated, "Business electives at the high school level don't have subject matter that is affected by culture, therefore culture is not at the forefront of importance in delivering the appropriate material in a way that is understood by all students" (student comment, exit survey, 2011). Similar views were shared by other students particularly those majoring in subject areas such as trades, physical education, mathematics, chemistry and physics.

The opportunity to innovate towards a blended learning format provided a unique opportunity to experiment with how to heighten the visibility of this content through live, intentional pedagogical modeling with technology. To do this, $50 \%$ of all in-class lectures were replaced with both instructor-made and websourced video and text-resources utilising a flipped model of instruction (Baker, 2000). This new asynchronous instruction provided significant opportunities for the instructor to customise the learning experiences in ways that enhanced the relevance of course content in relation to each individual's particular background. In other words, because it was no longer necessary for every student to hear the same lecture in the classroom (as in the F2F version), it was easier to incorporate student choice into accessing course content, resulting in more individualised digital pathways for learner engagement. Technological flexibility, then, provided teacher education students with novel opportunity to experience the CRP course content live within their own undergraduate learning experience, thereby, bringing greater visibility to its importance for consideration with future $\mathrm{K}-12$ students.

New digital learning resources were designed to include a range of options to connect with students' future practice. In particular, these allowed for further customisation based on students' pre-selected, K-12 subject teaching areas (e.g., mathematics, social studies). Optional resource selections (e.g., screencast, text, online video.) by students related to these different interests and were important for increasing the relevance of the course content, given that role of language, literacy, and culture varies across school subjects.

Initial student responses suggests digital innovation embedded within the core of the blended learning illustrated significant ways in which technology can support learner engagement by better meeting the needs of diverse learners in a teacher education course. The new, integrated virtual learning spaces offered flexible and effective means of customising the course material in order to increase its relevance across a broad range of student backgrounds and experiences that had not been possible in the F2F version, thereby supporting student engagement at both levels. As one student commented, "I thoroughly enjoyed having options for different readings and videos. It affected my learning in that I was in charge of it, never feeling 
like I had to do something. It was my choice.” (student comment, exit survey, 2013). Another student stated, "If there was a title I really enjoyed, I would watch/read all of the available information" (student comment, exit survey, 2013), indicating that even when given choices, students' engagement sometimes led them to make use of all available options.

This initial outcome offers an important lesson for teacher education. As such programs begin to experiment more with large virtual classrooms (e.g., MOOCs), each has the potential of bringing together increasingly heterogeneous groups of students. Greater instructional customisation may be critical to ensure that course content is responsive to student differences, thereby supporting engagement by all. Indeed, as students have greater opportunity to live these technological opportunities as part of their daily undergraduate class experience, pedagogical intentionality regarding the need for diversification in their own future K-12 classrooms may be made more visible within their meaning making as growing professionals.

Instructor narrative III - Inclusive education: Adapting instruction for students with special needs Blended learning innovation with the third F2F undergraduate teacher education course included further consideration of digital pedagogy to support learner engagement from both a socio-cultural and psychological perspective (Kahu, 2013). Increasingly, teacher education students not only include individuals from varied cultural, linguistic, and experiential backgrounds, but also students with disabilities. In fact, students with disabilities are accessing higher education at unprecedented levels; the fastest growing numbers of students within this group are students with invisible disabilities that affect learning or the ability to attend to instruction (Burgstahler, 2010).

In light of this trend, content in the F2F version of this course had included introducing students to inclusive education and approaches to adapting and enhancing classroom contexts for students with diverse needs. The new blended learning version added exploration of the principles of universal design for learning (UDL) (CAST, 2011) to better provide a live model from which undergraduate teacher education students might springboard their own curriculum designs in their future classrooms. UDL is intended to provide a framework for curriculum, teaching, learning, and assessment of learners who are diverse along many dimensions, including gender, ethnicity, socioeconomic status, age, ability, and disability (Burgstahler, 2010). Principles include (1) multiple means of representation (providing multiple ways for students to acquire and access information); (2) multiple means of action and expression (offering flexible ways for students to apply information and demonstrate their learning); and (3) multiple means of engagement (promoting student interest in content) (CAST, 2011).

Blended learning innovation included designing a new model of 50\% online instruction and 50\% F2F; this followed the same flipped model of teaching utilised in the other two courses (Baker 2000). Here, it was thought that flipping would inherently capture the first principle of UDL and thus was a perfect fit in helping the instructor use technology to make intentionality regarding UDL and student engagement even more visible for these pre-professional students. The instructor-made videos (screencasts) that students now were able to explore online before coming to the F2F classes taught key course concepts and summarised information from the print-based textbook. All screencasts included oral narration accompanied by PowerPoint presentations, graphic elements (diagrams, charts, images), videos and, most importantly, embedded English captions.

The use of these new digital screencasts enhanced acquisition and access to course information for teacher education students in several ways. Online access provided flexibility in both the time and location for completing course work. Screencasts were able to be watched in full, in part, and repeatedly, for the purposes of review or clarification, or to increase comprehension. As one student commented:

I liked having the online component to refer back to whenever I need a refresher or reminder, or simply needed to hear the explanation again to help deepen my understanding. I liked having the ability to complete the online portion in my own time, so for me this meant that I divided it up into smaller chunks rather than sitting through all of the screencasts in one sitting (student comment, exit survey, 2013).

Another stated, "I also like that everything is online and at my disposal. It's been amazing having all the screencasts for studying. I enjoy watching them and I feel that keeps me engaged” (student comment, exit 
survey, 2013). Thus, these new screencasts played an integral role in reducing the attentional resource demands that can be problematic for many undergraduate students in traditional lecture formats.

To further opportunities for multiple means of representation and illustrate this concept technologically, many course documents (PowerPoint slides, assignments, and quizzes) were also made available online in digital format compatible with text-to-speech software. Students could also customise documents in terms of size, contrast, color, layout, and font, which increased access for students with vision, learning, language, or reading difficulties and disabilities (CAST, 2011). In addition, in-class time was able to be repurposed to focus on reviewing key concepts taught in the screencasts; this was primarily to enhance and expand connections and relationships between and among course topics with students through participation in interactive activities and peer-to-peer and instructor-student discussions, thereby addressing multiple means of engagement.

Specific pathways were provided for students to apply information in both the synchronous and asynchronous course components providing concrete illustration of multiple means of action and expression. Screencasts incorporated guiding questions to support acquisition of key ideas and to promote student reflections on applicability of particular instructional approaches in elementary and secondary settings. Online discussion forums on topics generated by both instructors and students provided an additional medium for knowledge expression and sharing.

A major component related to the expression and demonstration of knowledge was also accomplished via newly repurposed course assessments. The blended leaning approach allowed for a variety of assessment methods including the new opportunity for undergraduate students to demonstrate their knowledge though completion of a multi-part case-study assignment. Assessment in the asynchronous environment was accomplished through quizzes, which, although timed, provided student flexibility with respect to access time and location. Students also benefited from receiving immediate Internet feedback upon completion of each quiz.

It is important to acknowledge that this experimentation to infuse UDL into an undergraduate teacher education blended delivery course is not a perfect model, since many aspects of the innovation do not yet meet UDL standards. Early responses from students, however, indicate this digital innovation in teacher education is an example of beginning steps in a journey to improve both the experience and academic outcome for students with diverse learning needs. Already statistics indicate students are choosing to attend F2F sessions more regularly than when the course was offered in a traditional lecture format. Further, students are accessing the asynchronous components regularly, and course grades have risen significantly in the blended format. Viewed as a digital solution towards de-stigmatising disability while at the same time changing attitudes about diversity and disability (Burgstahler, 2010), early student response suggests digital innovation of this kind may be helpful in illuminating issues of inclusiveness in student engagement for virtual learning spaces of all sizes.

\section{Data analysis part II}

Data from across all three blended learning course innovations were analyzed again, this time grouped into one large data pool. Researchers worked separately to identify reoccurring themes by sifting through the three instructor narratives and cross-checking emerging themes with student mid-term and exit survey comments. Upon completion, all came together for discussion and negotiation until points of convergence were identified in relation to the two research questions. Triangulation provided through examination of these multiple data sources by multiple researchers served to support both the validity of the data as well as lead to deeper understanding of the emerging constructs (Johnson, 1997).

\section{Results}

Analysis pointed to four key opportunities for technological innovation emerging from the qualitative data in relation to supporting student engagement within undergraduate virtual learning spaces. Each was revealed as important opportunities for digital intentionality, indicating moments for pedagogical intervention at the design stage of a virtual learning environment that could support learner engagement by undergraduate students. The researchers labeled these four pedagogical opportunities as: 
(1) digital resources

(2) scaffolding

(3) learner customisation

(4) the lived experience.

\section{Discussion}

These four threads of understandings emerging from the cross-course data analysis in research cycle one are noteworthy, given their revelation across three diverse types of undergraduate teacher education courses (i.e., elementary methods, secondary methods, educational psychology). Indeed, such congruence suggests commonalities regarding student engagement that may transcend discipline areas and, thus, are potentially integral to any digital innovation in undergraduate pre-service education.

As a result, we suggest pedagogical intentionality within any teacher education virtual learning space would do well to consider these four emerging ideas intersecting digital innovation and student engagement:

(1) multiple forms of digital resources for activating engagement: the design and inclusion of multiple forms of digital resources (e.g., readings, screencasts, videos, podcasts, online discussions, Web 2.0 social media) such that engagement activation is supported for different types of learners from both the psychological (e.g., self-efficacy, learner modality strengths) and socio-cultural perspective (e.g., cultural diversity, inclusion)

(2) scaffolding for deepening professional understanding: the design and inclusion of digital resources (e.g., short pedagogical vignettes) such that revisiting these learning objects within the virtual learning space can provide teacher education students with multiple opportunities for scaffolding - beginning with course content activation and deepening towards pre-professional understanding regarding the concept of engagement in the $\mathrm{K}-12$ classroom

(3) learner customisation for sustained engagement and meaning-making: the design and inclusion of digital assignments such that each is made flexible enough to support learner customisation; thereby supporting opportunity for students to take greater ownership of the learning process in relation to their future $\mathrm{K}-12$ practice

(4) promotion of a lived experience of student engagement: The design and inclusion of unique digital resources such that opportunities for students' lived experiences with learner engagement (e.g., UDL) are created; thereby supporting teacher educators' desires to model and scaffold intentionality regarding engagement possibilities with $\mathrm{K}-12$ students.

Intentionality regarding learner engagement is critical in the design of virtual learning spaces, since with the privileges of student flexibility in learning time and space (e.g., asynchronous), comes increased responsibility for individual student motivation. The four technological innovations, revealed by both instructors and students as playing a positive role in activating and sustaining engagement in the new blended learning environments in our research, hold promise for supporting diverse students in virtual learning spaces. Each involves design opportunities that can be developed and managed by the university instructor, and thus may offer practical, digital pathways for creating positive and observable support for a variety of student learners. The added bonus of having successfully created a lived experience of student engagement for teacher education students was important; thereby providing opportunity for heightened consciousness towards the possibilities of utilising technology to support K-12 students in these preprofessionals' future practice. This brought the final stage of student engagement (i.e., meaningful learning) into view and created reflection by all three professors on how they might continue to build on this digital design construct in future courses.

\section{Looking towards research cycle two}

We designed our action research study to inform and promote knowledge building through the flow of data from one cycle to the next. As we go forward with year two (i.e., research cycle two), the four pedagogical opportunities for digital innovation identified through the three professors' collective innovations will form the key focal points for our continued investigation. Adding quantitative data collected through digital analytics and newly designed survey instruments that examine students' use of these four digital design components will help us delve even deeper into the contribution that each pedagogical intervention might be making in terms of supporting student engagement. 
Embedding the instructors within the collective action of digital problem-solving and data collection was revealed as critical in the first research cycle for gaining new understanding regarding student engagement and virtual spaces. The enthusiasm exhibited by the three professors towards a willingness to engage in further digital innovation bodes well for this kind of research process, providing higher education with a transformational pathway for building technological capacity in the professoriate. It seems likely that future technological innovation in undergraduate programmes, whether small (e.g., blended) or large (e.g., MOOC), might also discover such dual benefits through the collaborative design of action research.

\section{Implications and future directions}

Examining the lessons learned through blended learning innovation in teacher education, has the potential to provide a much needed lens through which to view possibilities for building a rich repository of engaging, culturally responsive, and inclusive teaching and learning practices within a variety of virtual undergraduate spaces. Indeed, for a learning innovation to be considered sustainable, it should be about a consciousness towards supporting students' activation and sustainment of engagement, not simply completion. According to the instructors involved in the first cycle of our action research study, embedding technology within the core of an undergraduate course, as was both possible and necessary in blended learning, helped them support student engagement digitally, as well as bring greater visibility to their teacher education students regarding technological opportunities for supporting student engagement of all ages.

As we continue to collect data in research cycles two and three with more blended learning innovation, we suggest such blended learning experimentation could be integral to transforming teaching and learning at the local level of the institution, while exploring strategies for scaffolding outstanding principles of sociocultural learning practices into larger, online environments such as the MOOC 2.0. Irvine, Code, and Richards (2013) view the ongoing hype surrounding MOOCs as potentially "distracting leadership from focusing on alternative options for supporting the needs of learners” (p. 172). Others view this public excitement as an opportunity to bring attention to higher education's need to actively pursue innovation in regards to supporting contemporary learners. Sebastian Thrun's (i.e., founder of Udacity) statement that he had "aspired to give people a profound education - to teach them something substantial" with the xMOOC, but found that the "data was at odds with this idea" (Chafkin, 2013) provided an important reaffirmation of this challenge. Universities viewing this juncture in e-learning development as an opportunity will continue forward with their commitment towards teaching innovation by taking an even deeper look at how to redefine online formats (however massive!) to include the threads of excellent pedagogy surrounding student engagement.

Issues that will continue to require reflection during this research will include determining an appropriate balance between online instructional activities and building learning communities through F2F or synchronous learning. Optimising the deployment of academic staff time and energy in a way that both maximises student engagement and builds capacity for further technological innovation by the teacher education professoriate will also be important. Cost-effectiveness is critical within institutional structures and requires a transparency among the various levels of governance with a clear commitment to experimentation with 21st century learning formats. Blended learning has the potential to capture the best of both online and F2F interaction in undergraduate education, but translation of this capacity within larger formats such as MOOCs will require a greater attention towards the research on student engagement. It is through such continued research and reflection that opportunities for building stronger learning spaces in higher education, both in situ and virtually, can become a reality.

\section{Acknowledgements}

This research was supported in part with funds from the University of Alberta Digital Strategies Research \& Development Committee.

\section{References}

Agarwal, P., Bain, P., \& Chamberlain, R. (2012). The value of applied research: Retrieval practice improves learning and recommendations from a teacher, a principal, and a scientist. Educational Psychology Review, 24(3), 437-448. doi:10.1007/s10648-012-9210-2 
Australian Council for Educational Research (2010). Australasian survey of student engagement. Camberwell: Author. Retrieved from http://www.acer.edu.au/ausse

Baker, J. (2000). The 'classroom flip': Using web course management tools to become the guide by the side. In J. A. Chambers (Ed.), Selected papers from the 11th International Conference on College Teaching and Learning (pp. 9-17). Jacksonville, FL: Florida Community College at Jacksonville.

Bandura, A. (1997). Self-efficacy: The exercise of control. New York, NY: W. H. Freeman.

Bell, L. (Ed.) 2001. Preparing tomorrow's teachers to use technology: Perspectives of the leaders of twelve national educational associations. Contemporary Issues in Technology and Teacher Education, 1(4), 517-534. Retrieved from http://www.citejournal.org/

Bruner, J. (1991). The narrative construction of reality. Critical Inquiry, 18(1), 1-21.

Bryson, C., \& Hand, L. (2007). The role of engagement in inspiring teaching and learning. Innovations in Education and Teaching International, 44(4), 349-362. doi:10.1080/14703290701602748

Burgstahler, S. E. (2010). Universal design in higher education. In S. E. Burgstahler \& R. C. Cory (Eds.), Universal design in higher education: From principles to practice (pp. 3-20). Cambridge, MA: Harvard Education Press.

Casanovas, I. (2010). Exploring the current theoretical background about adoption until institutionalization of online education in universities: Needs for further research. Electronic Journal of e-Learning, 8(2), 73-84. Retrieved from http://www.ejel.org/main.html

CAST. (2011). Universal design for learning guidelines (version 2.0). Wakefield, MA: Author. Retrieved from http://www.cast.org/index.html

Caufield, M., Collier, A., \& Halawa, S. (2013, October 7). Rethinking online community in MOOCs used for blended learning. Educause Review Online, 1-11. Retrieved from http://www.educause.edu/ero/article/rethinking-online-community-moocs-used-blended-learning

Chafkin, M. (2013, November). Udacity’s Sebastian Thrun, godfather of free online education changes course. Fast Company. Retrieved from http://www.fastcompany.com/3021473/udacity-sebastianthrun-uphill-climb

Daniel J. (2012). Making sense of MOOCs: Musings in a maze of myth, paradox and possibility. Journal of Interactive Media in Education, 18, 3-12. doi:10.5334/2012-18

Francis, R., \& Shannon, S. (2013). Engaging with blended learning to improve students’ learning outcomes. European Journal of Engineering Education, 38(4), 359-369. doi:10.1080/03043797.2013.766679

Haggard, S. (2013). The maturing of the MOOC (BIS Research Paper No. 130). London: Department for Business Innovation and Skills. Retrieved from https://www.gov.uk/government/uploads/system/uploads/attachment_data/file/240193/13-1173maturing-of-the-mooc.pdf

Irvine, V., Code, J., \& Richards, L. (2013). Realigning higher education for the 21st century learner through multi-access learning. Journal of Online Learning \& Teaching, 9(2), 172-179. Retrieved from http://jolt.merlot.org/vol9no2/irvine_0613.pdf

Johnson, R. (1997). Examining the validity structure of qualitative research. Education, 118(3), 282-292.

Kahu, E. (2013). Framing student engagement in higher education. Studies in Higher Education, 38(5), 758- 773. doi:10.1080/03075079.2011.598505

Kemmis, S. (2001). Exploring the relevance of critical theory for action research: Emancipatory action research in the footsteps of Jurgen Habermas. In P. Reason \& H. Bradbury (Eds.), Handbook of action research: Participatory inquiry and practice (pp. 91-102). London: Sage.

Khan, S. (2012). The one world schoolhouse: Education reimagined. London: Hodder \& Stoughton.

Koehler, M., Mishra, P., \& Yahya, K. (2007). Tracing the development of teacher knowledge in a design seminar: Integrating content, pedagogy and technology. Computers \& Education, 49(3), 740-762. doi:10.1016/j.compedu.2005.11.012

Korn, M., \& Levitz, J. (2013, January 1). Online courses look for a business model. Wall Street Journal. Retrieved from http://online.wsj.com/

Kuh, G., Kinzie, J., \& Buckley, J., Bridges, B. K., \& Hayek, J. C. (2006). What matters to student success: A review of the literature. Bloomington, IN: National Postsecondary Education Cooperative. Retrieved from http://nces.ed.gov/npec/pdf/kuh_team_report.pdf

Ladson-Billings, G. (1995). Toward a theory of culturally relevant pedagogy. American Educational Research Journal, 32, 465-491. doi:10.3102/00028312032003465

Malone, T., \& Lepper M. (1987). Making learning fun: A taxonomy of intrinsic motivations for learning. In R. Snow \& M. Farr (Eds.), Aptitude, learning and instruction: Vol. III. Cognitive and affective process analysis (pp. 223-253). Hillsdale, NJ: Lawrence Erlbaum. 
McCarthy, J. (2010). Blended learning environments: Using social network sites to enhance the first year experience. Australasian Journal of Educational Technology, 26(6), 729-740. Retrieved from http://ascilite.org.au/ajet/submission/index.php/AJET/index

Moskal, P., Dziuban, C., \& Hartman, J. (2013). Blended learning: A dangerous idea? Internet \& Higher Education, 18, 15-23. doi:10.1016/j.iheduc.2012.12.001

Owston, R., York, D., \& Murtha, S. (2013). Student perceptions and achievement in a blended learning strategic initiative. Internet \& Higher Education, 18, 38-46. doi:10.1016/j.iheduc.2012.12.003

Polkinghorne, D. (1995). Narrative configuration in qualitative analysis. Qualitative Studies in Education, 8(2), 5-13. doi:10.1080/0951839950080103

Reason, P., \& Bradbury, H. (2001). Inquiry and participation in search of a world worthy of human aspiration. In P. Reason \& H. Bradbury (Eds.), Handbook of action research: Participatory inquiry and practice (pp.1-14). London: Sage.

Rodriguez, C. (2012). MOOCs and the AI-Stanford like courses: Two successful and distinct course formats for massive open online courses. European Journal of Open, Distance and E-Learning. Retrieved from http://www.eurodl.org

Schuetz, P. (2008). A theory-driven model of community college student engagement. Community College Journal of Research \& Practice, 32, 305-324. doi:10.1080/10668920701884349

Siemens, G. (2005). Connectivism: A learning theory for the digital age. International Journal of Instructional Technology \& Distance Learning, 2(1), 3-10. Retrieved from http:/www.itdl.org/

Skinner, B.F. (1976). About behaviorism. New York, NY: Doubleday.

Skorton, D., \& Altschuler, G. (2013, January 28). MOOCs: A college education online? Forbes. Retrieved from http://www.forbes.com/sites/collegeprose/2013/01/28/moocs-a-college-educationonline/

So, H., \& Brush, T. (2008). Student perceptions of collaborative learning, social presence and satisfaction in a blended learning environment: Relationships and critical factors. Computers \& Education, 51, 318-336. doi:10.1016/j.compedu.2007.05.009

Torrisi-Steele, G., \& Drew, S. (2013). The literature landscape of blended learning in higher education: The need for better understanding of academic blended practice. International Journal for Academic Development, 18(4), 371-383. doi:10.1080/1360144X.2013.786720

Trowler, V., \& Trowler, P. (2010). Student engagement evidence summary. York: Higher Education Academy.

Turney, C., Robinson, D., Lee, M., \& Soutar, A. (2009). Using technology to direct learning in higher education. Active Learning in Higher Education, 10(1), 71-83. doi:10.1177/1469787408100196

Vaughn, N. (2007). Perspectives on blended learning in higher education. International Journal on ELearning, 6(1), 81-94. Retrieved from http://www.editlib.org/p/6310/

Veletsiano, G. (2010). A small-scale adventure learning activity and its implications for higher education practice and research. In Education, 16(1), 89-104. Retrieved from http://ineducation.ca/ineducation/index

Vygotsky, L. S. (1978). Mind in society. Boston, MA: Harvard University Press.

Corresponding author: Amanda Montgomery, amanda.montgomery@ualberta.ca

Australasian Journal of Educational Technology (C) 2015.

\section{Please cite as:}

Montgomery, A.P., Hayward, D.V., Dunn, W., Carbonaro, M., \& Amrhein, C.G. (2015). Blending for student engagement: Lessons learned for MOOCs and beyond. Australasian Journal of Educational Technology, 31(6), 657-670. 